\title{
Mechanical Properties of Co-Cr Alloys for Metal Base Framework
}

\author{
${ }^{1}$ Andreja Carek, ${ }^{1}$ Jasenka Zivko Babic, ${ }^{2}$ Zdravko Schauperl, ${ }^{1}$ Tomislav Badel \\ ${ }^{1}$ Department of Prosthodontics, School of Dental Medicine, Croatia \\ ${ }^{2}$ Department of Materials, Faculty of Mechanical Engineering, Croatia
}

Correspondence: Andreja Carek, Department of Prosthodontics, School of Dental Medicine, Croatia, e-mail: catovic@sfzg.hr

\section{ABSTRACT}

Purpose: This study investigated the effect of two welding methods on the mechanical properties of a cobalt-chromium (Co-Cr) alloy for metal base framework.

Materials and methods: Fifty-four plates were cast for TIG and laser welding. Cobalt-chromium for plates were prepared and divided into three groups of 18 samples. Group 1 and 2 were cut at the center of the plate. Eighteen specimens were joint by using TIG (Primotec Phaser Mx1), and other 18 by laser (Nd:YAG laser). Specimens in the as-cast condition were used as control group (group 3). After joining, each specimen was microscopic analyzed and tested to flexural and dynamic failure. Failure loads were recorded and fracture strength calculated.

Results: The changes in microstructure and micro-hardness were studied in the heat-affected zones (HAZ) and unaffected zones. Microhardness values increased in the heat-affected zone (HAZ) and in welded material compared to the parent material. The ANOVA test showed a highly significant difference $(\alpha=0.05)$ between the joint strengths of the as-cast control specimens and, TIG and laser-welded joints. The flexural and dynamic strength of the joints were higher than those for the TIG-welded joints, and both were higher than the laser-welded joint strengths for the tested Co-Cr alloy.

Conclusions: Although laser is more popular, in our research TIG showed better results for flexural and dynamic strength.

Keywords: Dental welding, Co-Cr alloy, Mechanical properties.

\section{INTRODUCTION}

The benefits of prosthetic treatment in a biological environment depend primarily on the characteristics of the alloy used, i.e. on its composition, structure and on the body reaction. Dental Co-Cr alloys are widely used by clinicians because of their good mechanical properties and excellent corrosion resistance. ${ }^{1-9}$ Good mechanical properties of these alloys are a result of a multiphase structure, age hardening among alloy components and precipitation of carbides, which substantially increase their hardness. It mostly has to do with alpha phase and metallic compounds (carbides) type M23C6 which considerably affect on the material trait. The hardness of Co-Cr alloys is between 550 and $800 \mathrm{MPa}$ and tensile strength 145 and $270 \mathrm{MPa}$. ${ }^{4,6}$ Mechanical properties should assure technical and functional durability (long-life) of the dental appliances. Anticorrosive depends on surface chrome oxide passive film. ${ }^{9-13}$ The occlusal load can get as high as $900 \mathrm{~N}$ in molar region. Prostheses undergo to the cyclic dynamic and static loading, which results in stress concentration. ${ }^{13-16}$ Fatigue failure has been reported in removable partial dentures and clasps. Breaks and cracks of metal reconstructions can be repaired either with soldering or welding procedures. ${ }^{17-27}$ The common welding technologies in dentistry are single pulse tungsten inert gas (TIG) welding and laser. ${ }^{3,16,17,19,24-27}$ The main difference between TIG and laser is that the TIG applies "electric" energy, while laser applies "light” energy to the object. Welding has many advantages according to soldering. 1,3,16,17,19-21,26-29 For example, welding does not usually require a "third" low fusing alloy (solder) as additional material for joining two pieces together. In order to minimize volumetric reduction and distortions, the use of additional materials of the same composition and color as the welded alloy is needed. For TIG or laser welding, the energy required to melt alloy depends more on the alloy thermal conductivity than on its melting range. The optimal result will only be achieved if the most suitable energy and duration of the impulse are chosen. Welding must be carried out in an argon atmosphere. ${ }^{30-33}$ The joint shape is important for the material penetration depth. ${ }^{13,18,34}$ A weld should be homogenous, hard, anticorrosive with minimal heataffected zone (HAZ). 1,3,13,16-20,26-27,35-41

The objective of this study was to analyze the influence of two kinds of welding on the mechanical properties of base CoCr alloy.

\section{MATERIALS AND METHODS}

The Co-Cr alloy, Wisil M (Austenal, Köln, Germany), was selected. The chemical composition according to the manufacturer (mass\%) of the alloy is: Co 63.1, Cr 28, Mo 6, Mn 1, Si 0.8, W 0.6, C 0.5. This alloy is frequently used in Europe for metal base framework. According to the ISO standard for flexure testing (EN ISO 6871-1) 54 specimens (dimensions $32 \times 10 \times 1 \mathrm{~mm}$ ) were casted. The specimens were 
cleaned mechanically and chemically, and divided into three groups of 18 specimens: The first group for TIG (Primotec Phaser Mx1) welding, second group for laser (Nd:YAG laser) welding and third group was the control (non-weld) group. Specimens in the first two groups had cut in the middle with an abrasive disk extensively cooled and lubricated. Working parameters were argon flow of $5 \mathrm{~L} / \mathrm{min}$ with pressure of $1 \mathrm{bar}$, $60 \%$ strength and impulse length of $18 \mathrm{~m}$. Hercules hybrid laser (Interdent, Celje, Slovenia) was used for laser welding. Working parameters were argon with a pressure of 2-3 bars, laser beam width $0.7 \mathrm{~mm}, 290 \mathrm{~V}$ and impulse length of $11 \mathrm{~m}$. Before welding samples were sandblasted with $\mathrm{Al}_{2} \mathrm{O}_{3}$ particles in order to prevent reflection of laser lights and to improve the penetration of the weld. The plates were welded on both sides.

For metallographic analysis, the specimens were mounted in polymers, grinded, polished and etched. Microstructure of the basic material, the weld zone and heat-affected zone (HAZ) were analyzed by an inverted metallurgical light microscope Olympus GX51 and a scanning electronic microscope, Vega Tescan TS5136LS, in a high vacuum with a voltage of $30 \mathrm{kV}$.

The micro-hardness was measured with PMT-3 device, in the transversal cross-section of the basic material, HAZ and welded material, with a load of $2 \times 0.981 \mathrm{~N}$ (HV 0.2).

Specimens of all groups were exposed to a three-point bending test on testing instrument (VEB Werkstoffprüfmaschinen, Berlin, Germany) to determine their resistance to fatigue loading. Distance between two seating points was $24 \mathrm{~mm}$. Maximal applied force was $400 \mathrm{~N}$, and accuracy error of testing machine was less or equal $0.5 \%$ (class 0.5 ). Measurement range was from $0.4 \mathrm{~N}$ to $400 \mathrm{~N}$. The specimens were loaded at the weld line. Loading was continuous increasing $5 \mathrm{~mm} / \mathrm{min}$ until the specimen fractured or slid out under the seating points. During the load test, the forces and deflection was continuously measured and a corresponding diagram was made. Triplicates tests were run for all conditions.

Dynamic analysis was performed at room temperature, cross-head speed was set at a rate of $10 \mathrm{~mm} / \mathrm{min}$ on a dynamic mechanic machine (LRX, Loysd instruments, Fareham, UK). Distance of bars was $24 \mathrm{~mm}$ apart. For each specimen an upper (Fu) and lower (Fd) force limit was tested. The upper force limit is defined as $90 \%$, and the lower force limit as $20 \%$ of the force that caused the fracture. All specimens were loaded through a 1000 cycles, and the number of cycles at which fractures occurred were recorded.

Differences between the groups were tested for statistical significance by use of a one-way analysis of variance (ANOVA, $\alpha=0.05)$.

\section{RESULTS}

TIG and laser welds are shown in Figures $1 \mathrm{~A}$ and B. Microstructure differences among TIG and laser in HAZ and joint can be observed in Figures 2 to 3B. As-cast alloy has the typical dendrite microstructure with spherical carbide particles in the interdendrite regions. Microstructure of welds in both groups was similar to significantly smaller crystal particles and

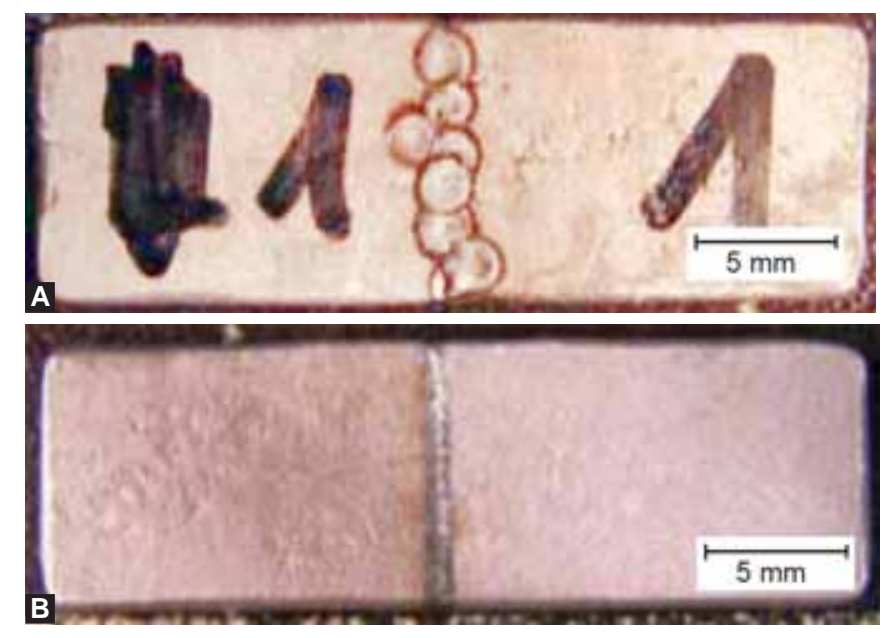

Figs 1A and B: Study specimens: (A) TIG-welded, (B) laser-welded

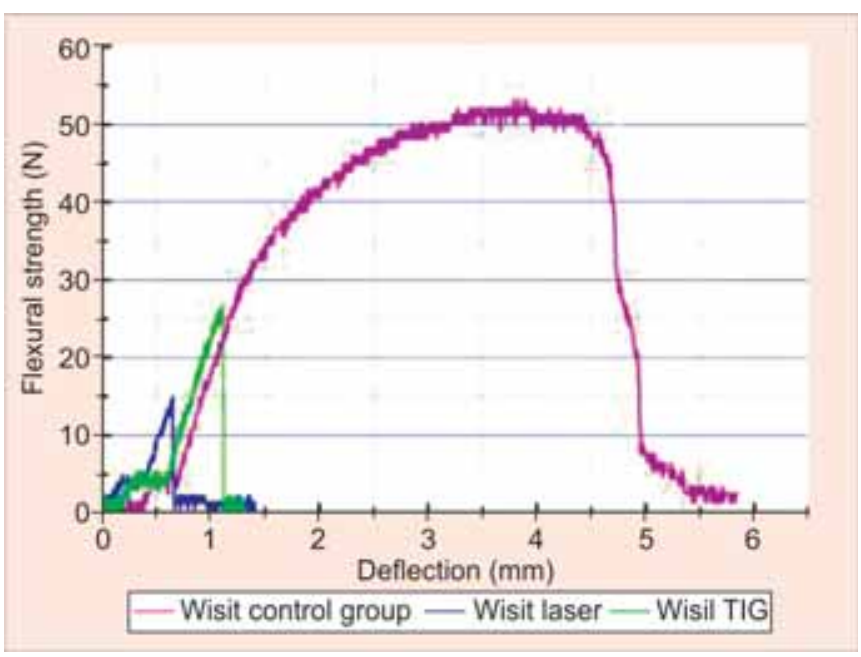

Fig. 2: Results of three-point bending test

uniform precipitation of carbides $\mathrm{M}_{23} \mathrm{C}_{6}$. Sporadically instances of the frangible $\sigma$-phase were found in the material of the weld. Considering that the HAZ is a critical location, those areas were analyzed utilizing a scanning electron microscope. Images were obtained using a back scatter detector (Figs 4A and B). Back-scattered electron images of Co-Cr-Mo alloys welded by laser show a large amount of precipitates along the interdendrite region in HAZ (Fig. 4A). Small amount of precipitates can be observed mainly in the HAZ of specimen welded by TIG (Fig. 4B). The median values of micro-hardness of 10 measurements are shown in Table 1. Micro-hardness values increased in the heat-affected zone (HAZ) and in welded material compared to the parent material. Laser-welded specimens demonstrated significantly higher micro-hardness values then those welded by TIG $(\alpha=0.05)$.

Table 1: Medium values of micro-hardness (HV 0.2)

\begin{tabular}{lccc}
\hline Sample & Parent material & HAZ & Weld \\
\hline TIG & 369 & 420 & 590 \\
Laser & 362 & 369 & 480 \\
As-cast & 350 & - & - \\
\hline
\end{tabular}



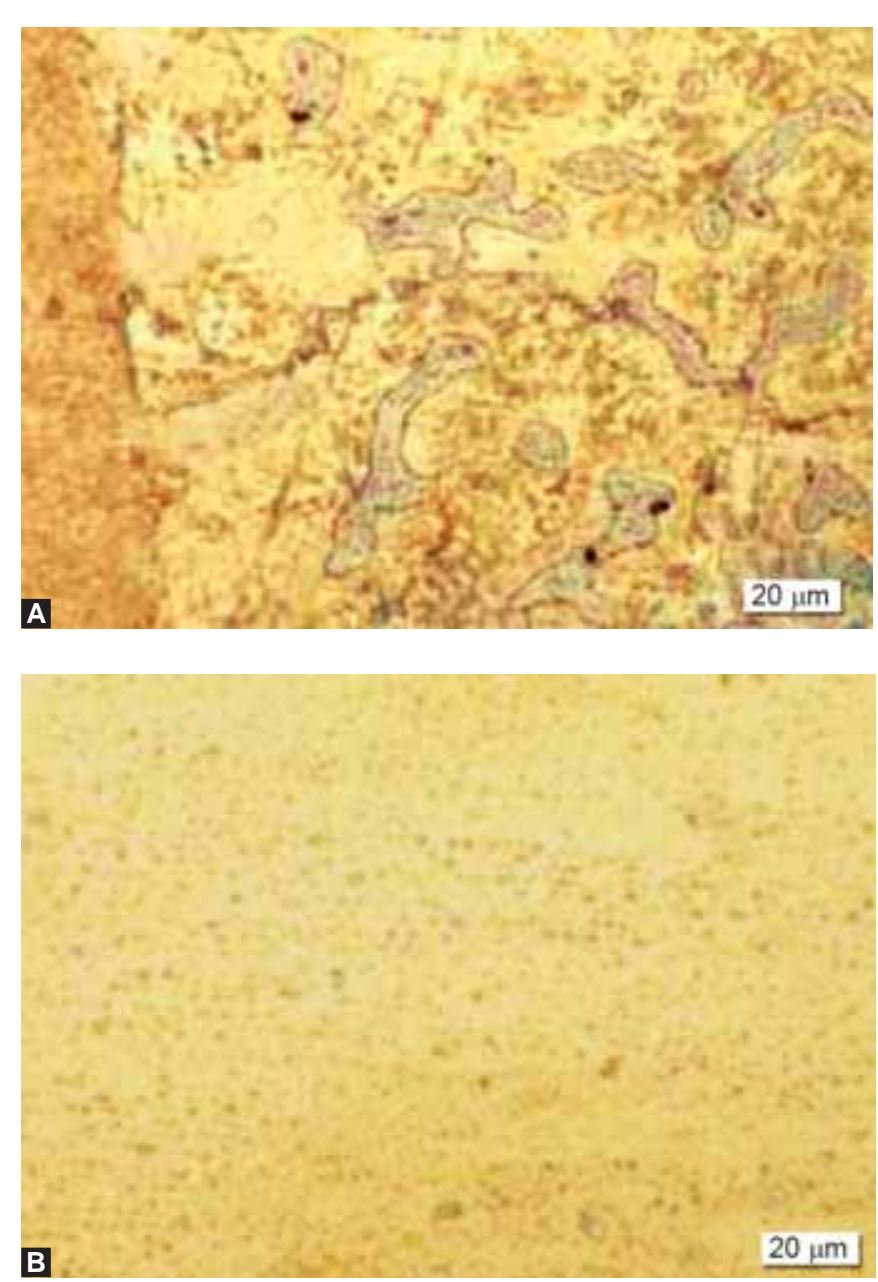

Figs $3 A$ and $B$ : Microstructure of the specimen welded by TIG: (A) HAZ, (B) welding material

The force and deformation of all three test groups were measured. From the measured forces and dimensions of the specimens (Fig. 5) the flexural strength was calculated.

The results for mechanical testing are shown in Figures 6A and B. A significant statistical differences between the control (non-weld) group and welded specimens were obtained $(\alpha=$ 0.05 ) (Table 2). The control group has a significantly higher bending strength than the welded specimens, with a considerably higher deformability rate (Figs 6A and B). Laserwelding resulted in lower flexural strength than TIG welding (Table 3). During dynamic analysis, total endurance was observed from the control group and TIG group. Laser group partially managed to endure the dynamic analysis. Five of nine laser-welded specimens fracture during the analysis. Fractographic analysis testing showed all fractures located in the heat affected zone or in weld material (Figs 7A and B). Features, progression and character of fractures are shown in the transversal cross-section (Figs 8A and B). Figure 8A shows the fracture line which progresses through the middle of the weld. Figure $8 \mathrm{~B}$ shows the intercrystal character which is distinctive for tension fractures.
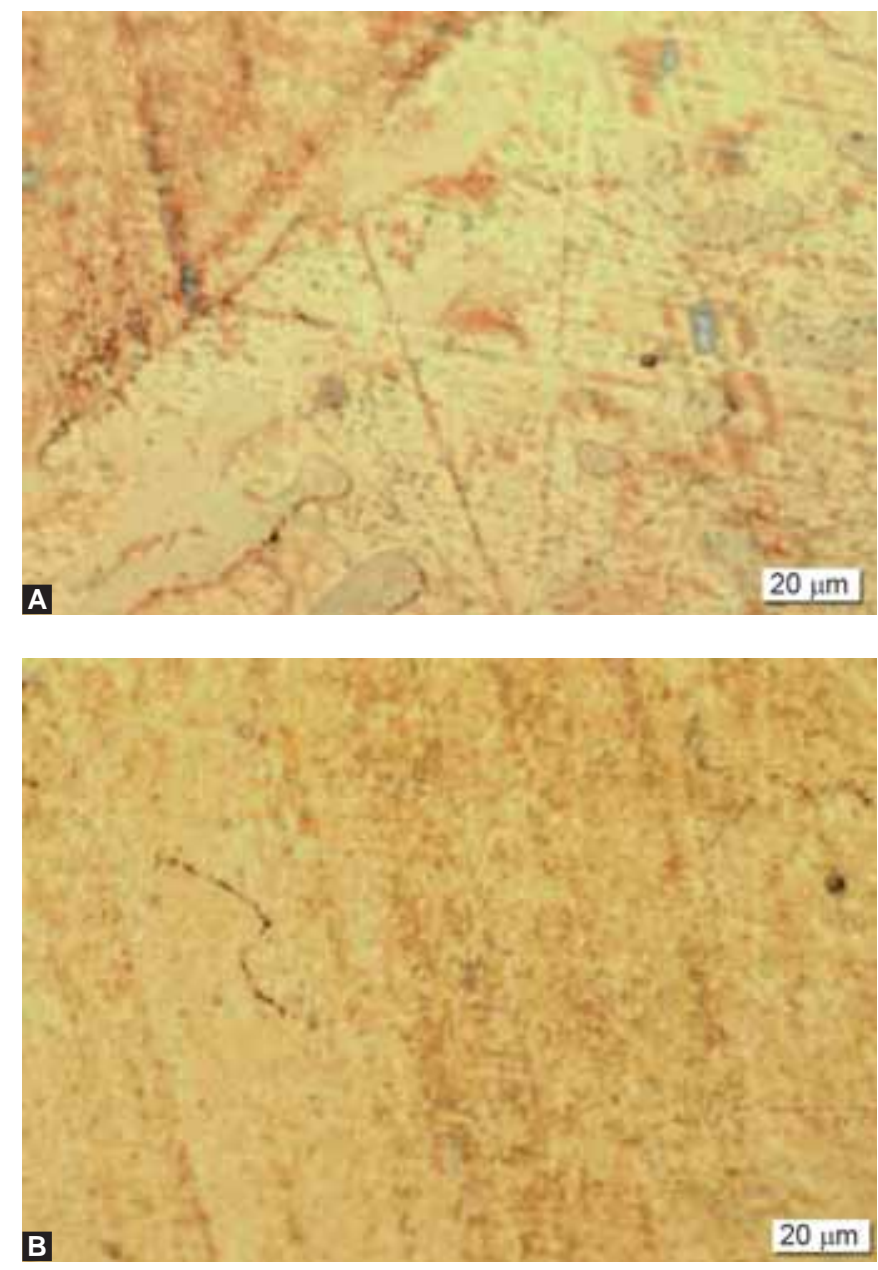

Figs $4 A$ and $B$ : Microstructure of the specimen welded by laser: (A) HAZ, (B) welding material

\section{DISCUSSION}

Microstructure and mechanical properties of welded joints depend on the welding parameters and technique (single layer, multilayer, unilaterally, multilaterally). The durability and hardness of the weld depend on the used welding technology. Welding process should be monitored by macroscopic or microscopic analysis. ${ }^{28,29}$ Argon produces a protective atmosphere around the weld and protects chemical reactions of molten metal with oxygen, nitrogen and other gases released during welding. Without protective atmosphere some metals could be colored, with higher hardness and brittleness. ${ }^{16,17,19,30}$ Watanabe et $\mathrm{al}^{30}$ considered that the laser welds made under argon gas required lower value of fatigue force. They proved that the use of argon shielding is necessary for effective laserwelding of CP Ti and Ti-6Al-7Nb but not for gold and Co-Cr alloy. Baba et al found no effect on the weld strength (flexural strength and fracture resistance) between Fe-Pt and $\mathrm{Co}-\mathrm{Cr}$ alloys. ${ }^{20}$ In our study, all samples were welded in protective atmosphere. Pressure of argon during laser welding was two to three bars, and during TIG four bars. 

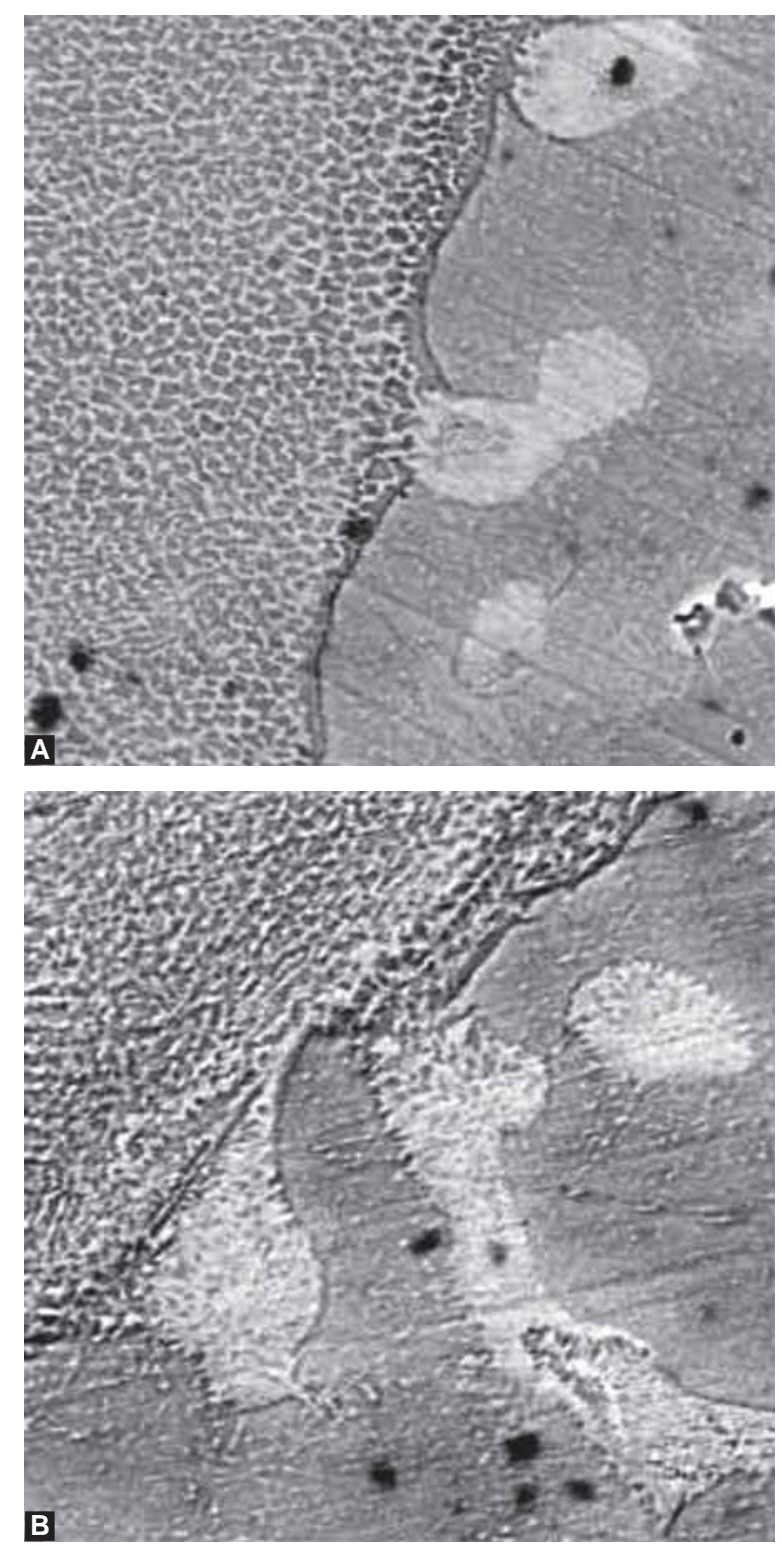

Figs 5A and B: SEM image of HAZ: (A) Laser weld, (B) TIG weld

Dobberstein and Dobberstein ${ }^{34}$ achieved good results with laser welded Co-Cr alloys. They mentioned the mechanical stability and the increased corrosion resistance as major advantages.

High temperatures caused internal stresses in laser-welded specimens. ${ }^{16,17,19}$ Deformation can be one of the consequences. Vahl and VanBenthem underscore the importance of minimum input of heat for ideal spot weld diameter. ${ }^{35}$ Baba et al ${ }^{36}$ investigate the effect of the output energy of laser welding and welding methods on the joints strength of Co-Cr alloy. For the $0.5 \mathrm{~mm}$ thick specimens, the force required to break the $0.5 \mathrm{~mm}$ laser-welded specimens at currents of 270 and $300 \mathrm{~A}$ was not statistically different $(p>0.05)$ from the results for the non welded control specimens. The force required to break the $1.0 \mathrm{~mm}$ specimens double-welded at a current of $270 \mathrm{~A}$ was the highest value among the $1.0 \mathrm{~mm}$ laser-welded specimens. The results suggested that laser-welding under the appropriate
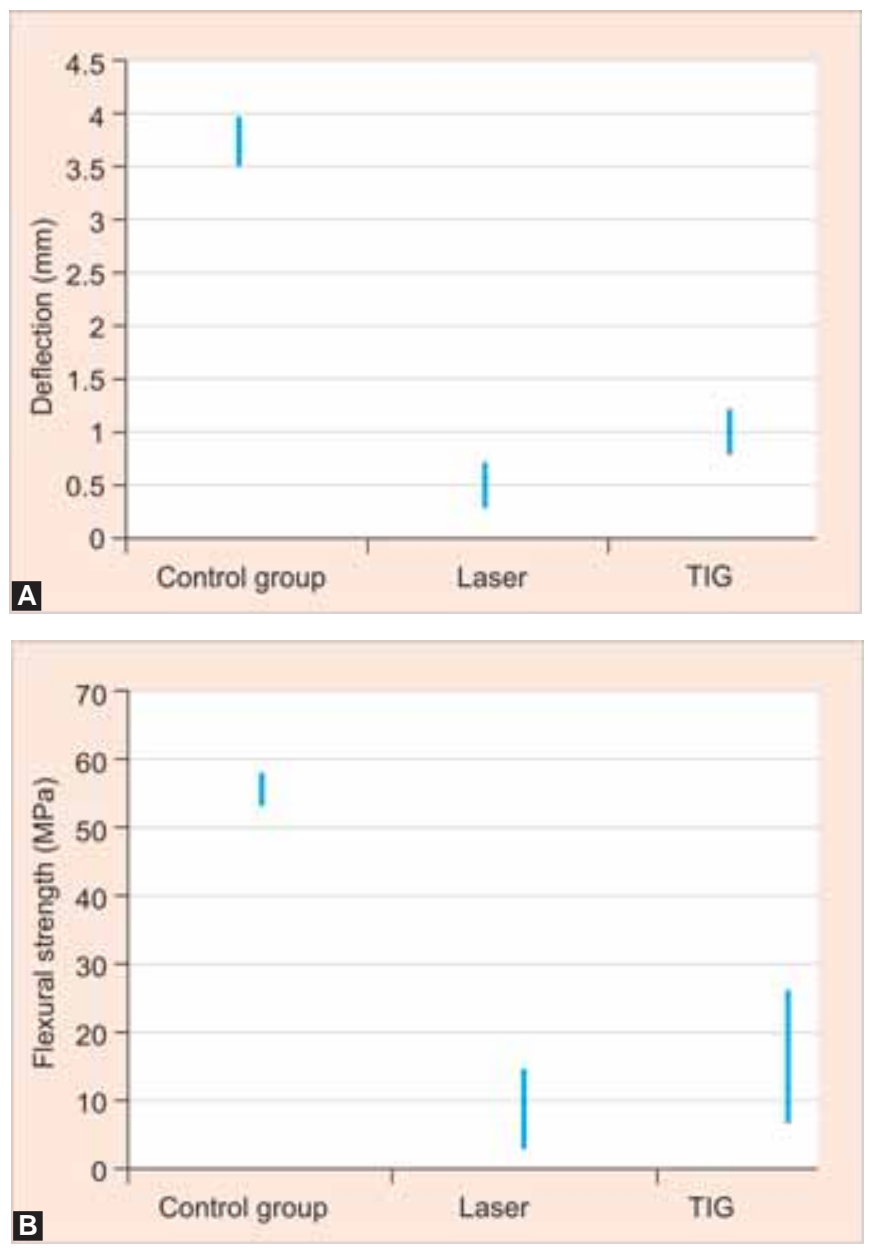

Figs $6 A$ and $B$ : Result of three-point bending test (A) deflection, (B) flexural strength

conditions improved the joint strength of cobalt-chromium alloy.

Topham et al proved that the welds made on both sides are stronger than unilaterally, regardless of the number of welding spots. Co-Cr samples, even bilaterally welded, were approximately half as strong as corresponding control specimens. The authors concluded that the percentage elongation is correlated with the fracture forces. ${ }^{37}$

Samples in our study were $1.0 \mathrm{~mm}$ thickness. According to the manufacturer's recommendation, the laser parameters were current of $300 \mathrm{~A}$, voltage of $290 \mathrm{~V}$ and pulse diameter $0.7 \mathrm{~m}$. Subsequently welding considerably reduces the static mechanical and dynamic endurance properties of the material. As-cast samples showed higher flexural strength than welded ones.

Na Badalung and Nicholls proved that the tensile strengths of the as-cast joints were higher than those for the laser-welded joints, and both were higher than the electric-brazed joint strengths. ${ }^{38}$

The results of this study indicated that no adequate penetrations depth, average $0.3 \mathrm{~mm}$, was one of the factors influenced of the break laser-welded joints under dynamic testing. 

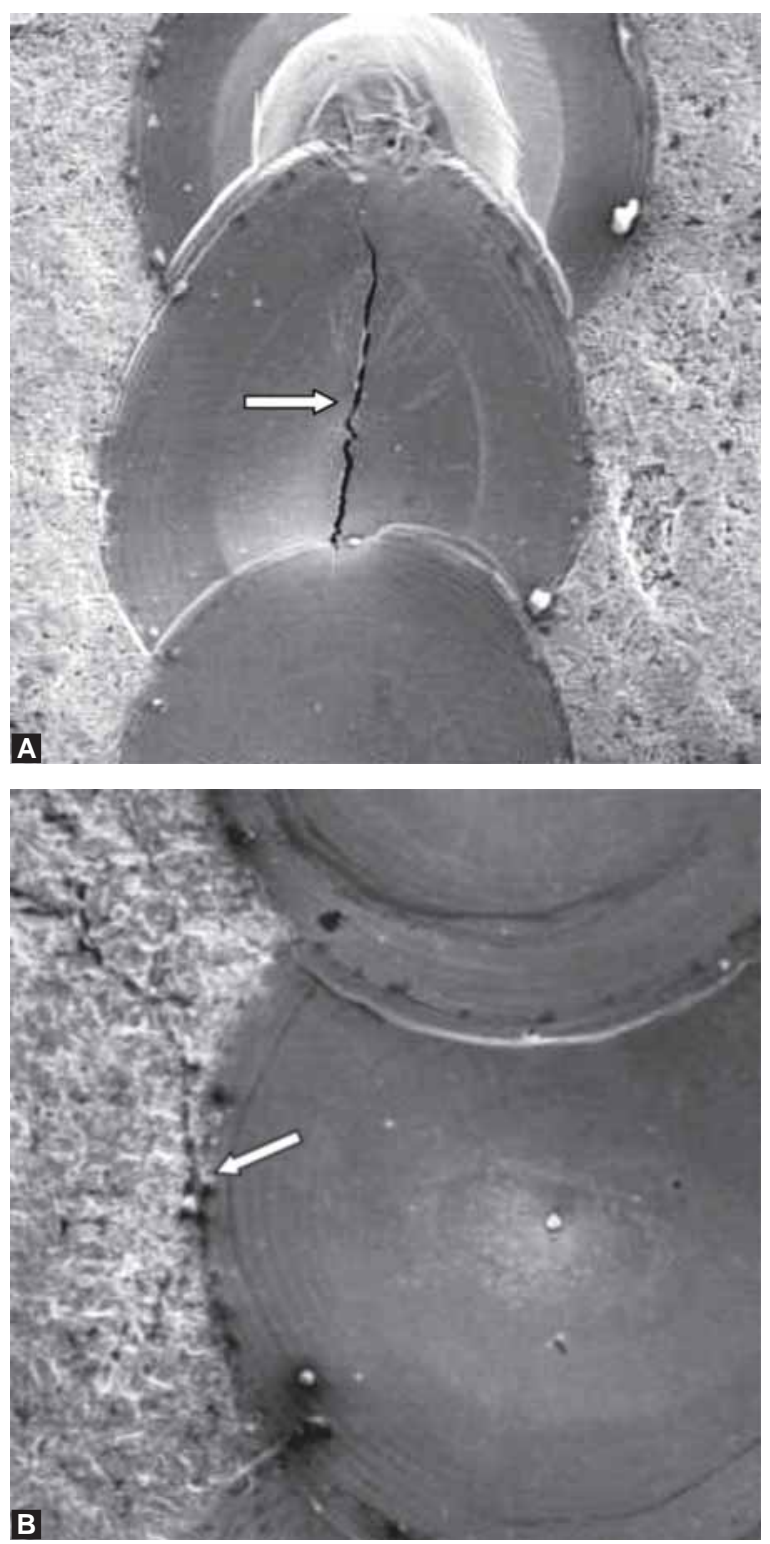

Figs 7A and B: SEM image (A) Fractures in the weld material, (B) Fractures in $\mathrm{HAZ}$

Rocha et $\mathrm{al}^{24}$ obtained better results of flexural strength welded by TIG system with and without additional material compared with laser and non-welded samples of Co-Cr alloys. Laser welding parameters were: $12 \mathrm{~m}$, repetition rate and $7.49 \mathrm{~kJ} / \mathrm{cm}^{2}, 1064 \mathrm{~nm}$ wavelength and TIG-welding parameters were : $10 \mathrm{~V}, 15-20 \mathrm{~A}$ and 12 seconds working time. These are one of the few authors who get better results with TIG welds than with laser process.

According to the data in this study, TIG-welded joints are clearly more resistant to fatigue stresses than those obtained by laser. This result may be due to the use of a powerful heat source (TIG) that was able to increase the size of the welded site without reducing the diameter of the welded transverse area. The main disadvantage of the use of the TIG system is its high equipment, material and manpower costs. Despite the better flexural strength results of the TIG system, laser-welding is the most recommended technique because it is quick, precise
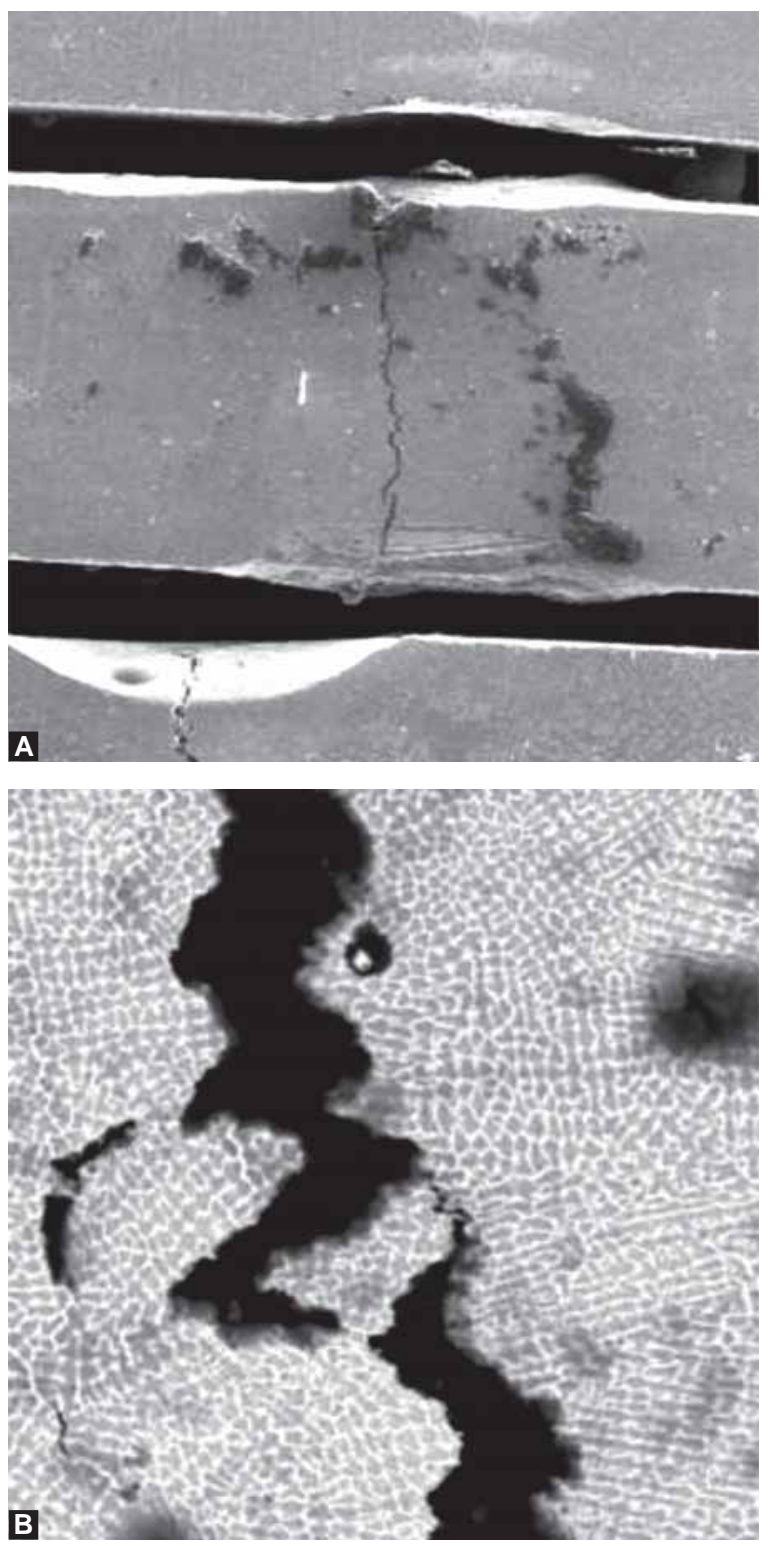

Figs 8A and B: SEM image of fractures in the transversal crosssection $(A)$ weld material, $(B)$ fracture under high magnification

and easy to be carried out. Additionally, laser welding also leads to little distortion and may be used for repairing different types of prostheses even when the weld point is close to resins of ceramics. This is possible because the periphery of the weld site remains at lower temperatures.

Bertrand et al proved different features of microstructure of weld material in relation to the parent material. The Co-Cr alloy presented excellent weld ability. A very important change in the microstructure due to the effect of the laser was pointed out in the welding zone, increasing its micro-hardness compared to the basic material, which coincides with the results of this study. They suggested the maximum depth of welding around $2 \mathrm{~mm}$, which is one of the usual thicknesses of the components which have to be repaired. ${ }^{22,23}$

Comparing laser and TIG-welded specimens, Roggensack et $\mathrm{al}^{41}$ achieved similar mechanical strength, while the TIG welded object showed a wide heat-affected zone with changes in the grain structure and increased hardness. 
The outcomes of this study showed that the control group has a significantly higher flexural strength and bending strength (dynamic analysis) than the welded specimens. TIG-welding yielded better results than Nd:YAG laser-welding. Connecting both methods is necessary to control the work under the microscope for better results.

\section{CONCLUSION}

Co-Cr alloy (Wisil M) shows exceptional welding capabilities. Due to heat generated during welding critical changes in the microstructure were visible. Instead of a multiphase microstructure, which is specific for this type of Co-Cr-Mo alloy, in the weld material extensive precipitation of $\mathrm{M}_{23} \mathrm{C}_{6}$ carbides and a significant portion of frangible $\sigma$-phase have been present in the weld material and heat-affected zone. The consequence was a negative adverse effect on the mechanical properties of the welds. Laser joints were harder than TIG ones. Micro-hardness of control group was the highest. Welds made by TIG technology have a significantly higher flexural strength and higher deformation rate than the ones done with a laser.

\section{ACKNOWLEDGMENTS}

Supported by The Ministry of Science, Technology and Sport (065-0650448-0439, 120-1201767-1762). The authors would like to thank the manufacturers for the donated material.

\section{REFERENCES}

1. Carek A, Žvko-Babić J, Schauperl Z. Microstructure analysis of base alloys joints. MED, Dublin, Ireland 2006;340-49.

2. Stojčević I, Carek A, Buković D, Heðever M. Influence of the partial denture on the articulation of dental and postalveolar Sounds. Collegium Antropologicum 2004;28:799-807.

3. Carek A, Žvko-Babić J, Schauperl Z, Jakovav M. Mechanical properties of Co-Cr welded alloy. Journal of Dental Research 2010;89:745.

4. Žvko-Babić J, Jerolimov V. Metals in dental prosthodontics. Zagreb: Školska knjiga 2005.

5. Dental materials classification system for cast alloys. Council on Dental Materials, Instruments, and Equipment. Journal of American Dental Association 1984;109:766.

6. Craig RG, Powers JM, Wataha JC. Dental materials: Properties and manipulation. St Louis: Mosby 2000.

7. Zupančić R, Legat A, Funduk N. Electrochemical and mechanical properties of cobalt-chromium dental alloy joints. Materials and technology 2007;6:295-300.

8. Žvko-Babić J, Ivanković V, Pandurić J. Quantitative thin-layer chromatographic of dental base alloys. Journal of Chromatography, Biomed Applications 1998;710:247-53.

9. Horvat ALM, Žvko-Babić J, Ivanković D, Babić S, KaštelanMacan M. Anodic sampling and TLC identification of dental alloys. Journal of Planar Chromatography 2001;14:426-29.

10. Bumgardner JD, Gerard PD, Geurtsen W, Leyhausen G. Cytotoxicity of precious and nonprecious alloys-experimental comparison of in vitro data from two laboratories. Journal of Biomedical Materials Research 2002;63:214-19.

11. Žvko-Babić J, Pandurić J, Alar V, Ivaniš T, Ivanković D. Identification of cobalt and chromium in prosthetic devices using thin-layerchromatography. Acta Stomatoliga Croatica 2000;34: 41-45.

12. Schubert G, Alar V, Žvko-Babić J, Turina S. Determination of chromium and nickel in high alloy steel by thin-layer chromatography with anodic sampling. Journal of Planar Chromatography 1998;11:460-63.

13. Wataha JC. Alloys for prosthodontic restorations. Journal of Prosthetic Dentistry 2002;87:351-63.

14. Strietzel R. Cobalt-Chromium alloys with veneering capacity. BEGO. Bremen 2008.

15. Žvko-Babić J, Pandurić J, Jerolimov V, Mioč M, PiŽeta I, Jakovac M. Bite force in subject with complete dentition. Collegium Antropologicum 2002;26:293-302.

16. Mosch J, Hoffmann A, Hopp M. Lightening in a Bottle: State of the art loining techniques in dental technology (Part 1). Continuing Education 2004;4:110-19.

17. Mosch J, Hoffmann A, Hopp M. Lightening in a Bottle (Part 3). Dental Dialogue 2004;4:37-51.

18. Wulfes H. Precision milling and partial denture constructions. International School BEGO. Bremen 2004.

19. Mosch J, Hoffmann A, Hopp M. Lightning in a Bottle. Soldering and welding are not the same. Dental Dialogue 2005;3:52-63.

20. Baba N, Watanabe I, Atsuta M, Okabe T. Penetration depth of Nd:YAG laser into dental casting alloys. 32nd Annual Meeting and Exhibition of the AADR 2003.

21. NaBadalung DP, Nicholls JI. Laser welding of cobalt-chromium removable partial denture alloys. Journal of Prosthetic Dentinstry 1998;79:285-90.

22. Bertrand C, Le Petitcorps Y, Albingre L, Dupuis V. The laser welding technique applied to the nonprecious dental alloys procedure and results. British Dental Journal 2001;190:255-57.

23. Bertrand C, Le Petitcorps Y, Albingre L, Dupuis V. Optimization of operator and physical parameters for laser welding of dental materials. British Dental Journal 2004;196:413-18.

24. Rocha R, Antônio LBP, Antonio BV. Flexural strength of pure $\mathrm{Ti}, \mathrm{Ni}-\mathrm{Cr}$ and $\mathrm{Co}-\mathrm{Cr}$ alloys submitted to Nd:YAG laser or TIG welding. British Dental Journal 2006;17:20-23.

25. Watanabe I, Wallace C. Bond strength of gold alloys laser welded to cobalt-chromium alloy. The Open Dentistry Journal 2008;2:109-13.

26. Carek A, Žvko-Babić J, Schauperl Z, Jakovac M. Influence of joining methods on microstructure and properties of dental alloys. In proceedings. Matrib 2006;274-82.

27. Carek A, Žvko-Babić J, Schauperl Z, Jakovac M. Characterization of laser and TIG joints of Co-Cr alloys. Acta Stomatologica Croatica 2009;43:354.

28. Carek A, Žvko-Babić J, Schauperl Z, Komar D, Jakovac M. Analysis of base alloy joints made by soldering and laser welding. Abstracts of 30th Annual Conference of EPA, London 2006;19.

29. Fornaini C, Vescovi P, Merigo E, Rocca JP, Mahler P, Bertrand C, Nammour S. Intraoral metal laser welding: A case report. Lasers in Medical Science 2010;25:303-07.

30. Fornanini C, Bertrand C, Rocca JP, Mahler P, Bonanini M, Vescovi P, Merigo E, Nammour S. Intra-oral laser welding: An in vitro evaluation of thermal increase. Lasers in Medical Science 2009;24:81-85.

31. Watanabe I, Topham S. Laser welding of cast titanuim and dental alloys using argon shielding. Journal of Prosthodontics 2006;15:102-07.

32. Crnac Z. Mjerenje i obrada parametara zavarivanja i zvuènih signala tijekom elektroluènog zavarivanja. Strojarski fakultet u Slavonskom Brodu. Dipomski rad 2006. 
33. Toyoda M, Mochizuki M. Control of mechanical properties in structural steel welds by numerical simulation of coupling among temperature, microstructure, and macro-mechanics. Science and Technology of Advanced Materials 2004;5: 255-66.

34. Watanabe I, Chang J, Chiu Y. Dimensional change of laserwelded gold alloy induced by heat. Wiley Inter Science 2004.

35. Dobberstein H, Dobberstein H, Orlick H, Fischer P, Zuhrt R. Experimental studies of the laser welding of Co-Cr alloys using a pulsed Nd:YAG-laser. Zahn-, Mund-, und Kieferheilkunde mit Zentralblatt 1989;77:578-79.

36. Vahl J, van Benthem H. Laser in der Zahnmedizin, Quintessence 1992;32:142-72.
37. Baba N, Watanabe I, Tanaka Y, Hisatsune K, Atsuta M. Joint properties of cast Fe-Pt magnetic alloy laser-welded to $\mathrm{Co}-\mathrm{Cr}$ alloy. Dental Materials Journal 2005;24:550-54.

38. Topham DS, Watanabe I, Baba N, Okabe T. Mechanical properties of laser-welded dental casting alloys. IADR San Anton 2003.

39. NaBadalung DP, Nicholls JI. Laser welding of a cobaltchromium removable partial denture alloy. Journal of Prosthetic Dentistry 1998;79:285-90.

40. Roggensach M, Walter mH, Boning KW. Studies on laser plasma welded titanium. Dental Materials 1993;9:104-07.

41. Carek A, Žvko-Babić J, Schauperl Z, Jakovac M. Macroscopic analysis of Co-Cr base alloys joints. Acta Stomatol Croat 2007; 41:216-24. 